\title{
EMPLOYEE RETENTION AND RECRUITMENT INCENTIVES FOR A GROWING MILLENNIAL WORKFORCE
}

Hadley Leavell, Sam Houston State University, U.S.A.

Balasundram Maniam, Sam Houston State University, U.S.A.

Neil Mayberry, Sam Houston State University, U.S.A.

dx.doi.org/10.18374/JABE-17-3.5

\begin{abstract}
Employee retention and recruitment should be a major concern for organizations as the Millennial generation now replaces the Baby Boomers as the nation's workforce. This paper looks at different working environments that can help reduce turnover while increasing the branding of companies as a desired place to work for recruitment purposes. Implementing new working environments can present a financial burden on employers; however, doing nothing to increase recruiting and retention ratios proves to be detrimental to an organization's success. This is an examination of the employee-driven benefits that organizations must provide and understand in the new work culture.
\end{abstract}

Keywords: Recruiting, retention, turnover, Millennials, toxic work environments, human resources 